\title{
Neoplastic transformation of porcine mammary epithelial cells in vitro and tumor formation in vivo
}

\author{
A. R. Rowson-Hodel ${ }^{1,2+}$, R. Manjarin ${ }^{1,3+}$, J. F. Trott' ${ }^{1}$ R. D. Cardiff ${ }^{4}$ A. D. Borowsky ${ }^{4}$ and R. C. Hovey ${ }^{1 *}$
}

\begin{abstract}
Background: The mammary glands of pigs share many functional and morphological similarities with the breasts of humans, raising the potential of their utility for research into the mechanisms underlying normal mammary function and breast carcinogenesis. Here we sought to establish a model for the efficient manipulation and transformation of porcine mammary epithelial cells (pMEC) in vitro and tumor growth in vivo.

Methods: We utilized a vector encoding the red florescent protein tdTomato to transduce populations of pMEC from Yorkshire -Hampshire crossbred female pigs in vitro and in vivo. Populations of primary PMEC were then separated by FACS using markers to distinguish epithelial cells (CD140a-) from stromal cells (CD140a+), with or without further enrichment for basal and luminal progenitor cells (CD49f+). These separated pMEC populations were transduced by lentivirus encoding murine polyomavirus T antigens (Tag) and tdTomato and engrafted to orthotopic or ectopic sites in immunodeficient NOD.Cg-Prkdc ${ }^{\text {cid }} / 12 \mathrm{rg}^{\mathrm{tm} / \mathrm{Wj} /} / \mathrm{SzJ}$ (NSG) mice.
\end{abstract}

Results: We demonstrated that lentivirus effectively transduces PMEC in vitro and in vivo. We further established that lentivirus can be used for oncogenic-transformation of pMEC ex vivo for generating mammary tumors in vivo. Oncogenic transformation was confirmed in vitro by anchorage-independent growth, increased cell proliferation, and expression of CDKN2A, cyclin A2 and p53 alongside decreased phosphorylation of Rb. Moreover, Tag-transformed CD140a- and CD140a-CD49f + pMECs developed site-specific tumors of differing histopathologies in vivo.

Conclusions: Herein we establish a model for the transduction and oncogenic transformation of PMEC. This is the first report describing a porcine model of mammary epithelial cell tumorigenesis that can be applied to the study of human breast cancers.

Keywords: Breast cancer model, Microenvironment, Lentivirus transformation, Xenograft, Pig

\section{Background}

Preclinical studies of breast cancer are limited by a lack of suitable models recapitulating aspects of human physiology and the biology of the human breast. Approximately $90 \%$ of cancer treatments stemming from preclinical screens performed using xenografts in rodents fail during clinical trials [1], highlighting intrinsic genetic, physiological $[2,3]$ and morphological [4] differences between humans and mice. The pig offers a promising alternative to traditional rodent models given they

\footnotetext{
*Correspondence: rchovey@ucdavis.edu

${ }^{\dagger}$ Equal contributors

'Department of Animal Science, University of California Davis, One Shields

Avenue, Davis, CA 95616, USA

Full list of author information is available at the end of the article
}

share pronounced genomic [5] and biological [6] similarities to humans. As such, pigs have increasingly become an integral species for translational research, particularly for preclinical toxicology studies and as a biomedical model for human cardiovascular, integumentary and gastrointestinal systems [7].

While the mammary glands of female pigs have only been infrequently cited as a model for the human breast, they closely recapitulate several important aspects of human breast biology. Development of the mammary tissue in pigs from embryogenesis [8] through puberty [9] and gestation [10] parallels that of the human breast [11]. While pigs have an average of 10-14 mammary glands, each has multiple (2-4) galactophores that drain 
to the nipple and form the primary duct from which the parenchymal tissue develops [12]. Humans also have multiple galactophores per nipple, while the mouse has only one [13]. The histomorphology of the porcine mammary gland and human breast has been similarly described as having terminal ductal lobular units (TDLU) embedded within fibrous inter-and intralobular connective tissues $[9,11]$, which contrasts to the simple ductal network and adipose-rich stroma of the mouse mammary gland [4]. Importantly, intrinsic structural differences between the mammary glands of rodents and humans likely influence tumorigenic risk given that the stroma directs proliferative, morphogenic and hormonal responses by the epithelium [14-16]. Furthermore, the relative abundance of different TDLU morphotypes in the human breast can influence breast cancer risk, where the least-differentiated TDLU type 1 (TDLU-1) is most prone to transformation [17]. A porcine model of human breast cancer would stand to address many of these interactions that underlie breast development and tumorigenesis [18]. Moreover, the size and positioning of the voluminous mammary glands will allow for the assessment of multiple treatments or endpoints within an animal and over time using serial biopsies [19].

Further to the above, few reports detail methods to isolate and genetically manipulate the mammary epithelial cells (pMEC) in pigs. The objective of this study was to establish methods of lentivirus-mediated transformation of pMEC as a first step toward developing a novel model for human breast cancer. We hypothesized pMEC would undergo oncogene-induced transformation to yield tumors with a histopathology resembling human breast cancers. Herein, we report the successful lentiviral transduction of porcine mammary cells in vitro and tissue in vivo, formation of tumors by transformed pMEC in immunocompromised mice, and the precocious expansion of TDLU when transformed pMEC were isografted into the pig mammary gland.

\section{Methods}

\section{Experimental design}

We initially conducted experiments to determine the efficiency of using lentivirus for the transduction of pMEC in vitro and in vivo. In study one we sought to develop and optimize methods for the collection and dissociation of mammary tissue from nulliparous pigs for transduction in vitro. In study two we transduced pig mammary tissue in vivo by direct instillation of non-oncogenic lentivirus into the mammary gland duct or parenchyma. For study three, we sought to determine whether pMEC transduced with non-oncogenic lentivirus in vitro could develop typical mammary structures when transplanted back to the mammary fat pads of respective donor pigs. Finally, in studies four and five, pMEC were transformed in vitro by oncogenic lentivirus and either isografted to the mammary gland of donor pigs (study four) or xenografted to the mammary fat pad of immunocompromised mice (study five).

\section{Animals}

All experimental protocols for animal experimentation underwent prior ethical review and were approved by the UC Davis Animal Care and Use Committee following guidelines set forth by the Association for Assessment and Accreditation of Laboratory Animal Care and the Guide for the Care and Use of Agricultural Animals in Research and Teaching (protocol \#17675). For study one and study five, mammary tissue was obtained at necropsy from healthy nulliparous Yorkshire $\times$ Hampshire pigs obtained from the specific pathogen-free swine facility at UC Davis when they were $3-5$ months of age ( $n=8$ and $n=4$, respectively). For study two ( $n=9$ pigs from two litters), study three $(n=8$ pigs from two litters), and study four ( $n=4$ pigs from two litters) pigs were healthy, experimentally naïve 4 week-old Yorkshire $\times$ Hampshire females. For studies two, three and four, piglets were selected that possessed at least twelve mammary glands, which permitted an individual pig to carry experimental treatments and controls within separate mammary glands. Piglets were housed indoors in a temperaturecontrolled facility $\left(25-27^{\circ} \mathrm{C}\right)$, as littermate pairs, were fed twice daily and had ad libitum access to water. Pigs were monitored daily for any changes in behavior or health status. During surgical procedures, pigs were assessed for changes in body temperature, heart rate and respiration. All surgical procedures involving pigs were carried out in a disinfected surgical suite designed for accommodating large animals.

In study five, 20 experimentally naïve female $N O D$ scid gamma (NOD.Cg-Prkdc ${ }^{\text {scid }} \mathrm{Il2} 2 \mathrm{rg}^{\text {tm } 1 \text { Wjl }} / \mathrm{SzJ}$ (NSG)) mice (The Jackson Laboratory, Sacramento, CA; $n=4$ per pMEC line) between 4 and 35 weeks of age (Table 1) were maintained in littermate groups with ad libitum access to food and water. Mice were housed in a pathogen-free barrier facility under conditions of constant temperature $\left(20-23{ }^{\circ} \mathrm{C}\right)$, humidity $(45-65 \%)$, and a $14 \mathrm{~h}$ light $/ 10 \mathrm{~h}$ dark cycle. Tumor formation was assessed weekly by palpation, and tumor diameter recorded every $2 \mathrm{~d}$ once they reached $1 \mathrm{~mm}$ diameter. During surgical procedures, mice were monitored for toe-pinch reflex and respiration rate. Surgical procedures were carried out within a disinfected biosafety cabinet to minimize pathogen exposure.

Pigs in study two received daily $17 \beta$-estradiol injections (IM, $0.1 \mathrm{mg} / \mathrm{kg}$; Sigma Aldrich, St. Louis, MO) for 7d after lentivirus instillation to stimulate MEC proliferation [9]. Similarly, pigs in studies three and four received daily $17 \beta-$ estradiol for $7 \mathrm{~d}$ prior to excision of mammary tissue. Upon 
Table 1 pMEC were sorted to remove fibroblasts (CD140-), and some selected for expression of CD49f or tdTomato, and then transduced at various passages ( $\mathrm{P}_{\mathrm{T}}$ ) with one of the lentiviral constructs PGK-Tantigen (PGKT), CMV-tdTomato (CMVT) or PGKT-CMVT (PTCT)

\begin{tabular}{|c|c|c|c|c|c|c|c|c|c|c|c|c|c|}
\hline Cell line & FACS & $\mathrm{P}_{\mathrm{T}}$ & In vitro morphology & Number & Age & $P_{1}$ & Cells (\#) & Matrix & Site & $E+P$ & $\begin{array}{l}\text { Tumor diameter } \\
(\mathrm{mm})\end{array}$ & $\begin{array}{l}\text { Weeks } \\
\text { carried }\end{array}$ & in vivo characteristics \\
\hline ss071712 PGKT & CD140- & \multirow[t]{2}{*}{1} & \multirow[t]{4}{*}{ Cobblestone, no foci } & \multirow[t]{2}{*}{3} & \multirow[t]{2}{*}{$67 d$} & 6 & $1 \times 10^{5}$ & Hydrogel & MG & No & $\mathrm{N} / \mathrm{a}$ & 16.7 & \multirow[t]{2}{*}{ N/a } \\
\hline ss071712 CMVT & CD140- & & & & & 6 & $1 \times 10^{5}$ & Hydrogel & MG & No & $\mathrm{N} / \mathrm{a}$ & 16.7 & \\
\hline ss071712 PGKT & CD140- & \multirow[t]{2}{*}{1} & & \multirow[t]{2}{*}{7} & \multirow[t]{2}{*}{$74 d$} & 6 & $1 \times 10^{5}$ & Hydrogel & MG & No & $\mathrm{N} / \mathrm{a}$ & 15.7 & \multirow[t]{2}{*}{ N/a } \\
\hline ss071712 CMVT & CD140- & & & & & 6 & $1 \times 10^{5}$ & Hydrogel & MG & No & $\mathrm{N} / \mathrm{a}$ & 15.7 & \\
\hline 27-3 РТСТ & CD140-tdTomato+ & \multirow[t]{2}{*}{1} & \multirow[t]{2}{*}{ Foci, radial outgrowth } & \multirow[t]{2}{*}{4} & \multirow[t]{2}{*}{$30 d$} & 7 & $5 \times 10^{5}$ & Hydrogel & MG & No & $<1 \mathrm{~mm}$ & 19.5 & Normal ductal epithelium \\
\hline 27-3 РТСТ & CD140-tdTomato+ & & & & & 7 & $5 \times 10^{5}$ & Hydrogel & SC (Rear) & No & $\mathrm{N} / \mathrm{a}$ & 19.5 & N/a \\
\hline 28-3 РТСТ & CD140- & \multirow[t]{2}{*}{1} & \multirow[t]{2}{*}{ Elongated, some foci } & \multirow[t]{2}{*}{4} & \multirow[t]{2}{*}{$30 d$} & 10 & $5 \times 10^{5}$ & Hydrogel & MG & No & $15.3 \pm 1.5$ & 18.5 & \multirow[t]{2}{*}{ Fibrosis, vimentin positive } \\
\hline 28-3 РТСТ & CD140- & & & & & 10 & $5 \times 10^{5}$ & Hydrogel & SC (Rear) & No & $12.3 \pm 1.1$ & 18.5 & \\
\hline 27-1 PTCT & CD140-tdTomato+ & \multirow[t]{2}{*}{1} & \multirow[t]{2}{*}{ Cobblestone, no foci } & \multirow[t]{2}{*}{4} & \multirow[t]{2}{*}{$30 d$} & 11 & $5 \times 10^{5}$ & Hydrogel & MG & No & $\mathrm{N} / \mathrm{a}$ & 36.4 & \multirow[t]{2}{*}{ N/a } \\
\hline 27-1 РТСТ & CD140-tdTomato+ & & & & & 11 & $5 \times 10^{5}$ & Hydrogel & SC (Rear) & No & $\mathrm{N} / \mathrm{a}$ & 36.4 & \\
\hline 28-6 РТСТ & CD140-tdTomato+ & \multirow[t]{2}{*}{1} & \multirow[t]{2}{*}{ Foci, rapid proliferation } & \multirow[t]{2}{*}{4} & \multirow[t]{2}{*}{$30 d$} & 11 & $5 \times 10^{5}$ & Hydrogel & MG & No & $<1 \mathrm{~mm}$ & 42 & Fibrosis, squamous epithelium \\
\hline 28-6 PTCT & CD140-tdTomato+ & & & & & 11 & $5 \times 10^{5}$ & Hydrogel & SC (Rear) & No & $\mathrm{N} / \mathrm{a}$ & 42 & $\mathrm{~N} / \mathrm{a}$ \\
\hline ss020513_1 PTCT & CD140- CD49f+ & \multirow[t]{2}{*}{1} & \multirow[t]{2}{*}{ Cobblestone, no foci } & \multirow[t]{2}{*}{4} & $102 d$ & 3 & $4 \times 10^{5}$ & Hydrogel & SC (Shoulder) & No & $5.3 \pm 0.6$ & 32 & \multirow{3}{*}{$\begin{array}{l}\text { Glandular, squamous epithelium, } \\
\text { CK8/18 positive }\end{array}$} \\
\hline ss020513_1 PTCT & CD140- CD49f+ & & & & \multirow[t]{2}{*}{$242 d$} & 3 & $1 \times 10^{6}$ & Matrigel & SC (Flank) & Yes & $6.0 \pm 0.4$ & 10 & \\
\hline ss020513_2 PTCT & CD140- CD49f+ & 1 & Cobblestone, no foci & 4 & & 3 & $8 \times 10^{5}$ & Matrigel & SC (Flank) & Yes & $6.2 \pm 1.2$ & 10 & \\
\hline ss082112_PTCT & CD140- & 6 & \multirow[t]{2}{*}{ Cobblestone, no foci } & 4 & $59 d$ & 10 & $1 \times 10^{6}$ & Matrigel & MG & Yes & $<1 \mathrm{~mm}$ & 10.6 & Normal ductal epithelium \\
\hline ss082112_PTCT & CD140- & 6 & & & & 11 & $1 \times 10^{6}$ & Matrigel & SC (Rear) & Yes & $7.21 \pm 0.2$ & 10.6 & Glandular, squamous epithelium \\
\hline
\end{tabular}

NSG mice $(n=3-7)$, at various ages, were injected with cells at various passages post-transduction (P) in hydrogel or Matrigel into mammary gland fat pads (MG) or subcutaneously (SC), with or without implanted estrogen $(E)$ and progesterone $(P)$ pellets. Cells were grown in the mice for up to 42 weeks and the widest diameter ( \pm SEM) and features of growths are indicated 
reinstillation of lentivirus-transduced cells, a $17 \beta$-estradiol/ cholesterol pellet $(0.05 \mathrm{mg} / \mathrm{kg})$ was placed subcutaneously, reducing the need for daily hormone injections. All pigs serving as donors for mammary tissue received penicillin intramuscularly $24 \mathrm{~h}$ prior to tissue collection to reduce the potential bacterial contamination of cultures. NSG mice carrying pMEC lines ss020513_1 and ss020513_2 $(n=4)$ and ss082112 $(n=4)$ received a pellet containing $2 \mu \mathrm{g} 17 \beta$ estradiol and $0.75 \mathrm{mg}$ progesterone (Sigma-Aldrich) at the time of cell injection to promote the proliferation of engrafted cells.

\section{Primary mammary cell isolation}

In studies one and four, immediately following exsanguination of pigs, the skin was disinfected, the nipple retracted and $\sim 1 \mathrm{~g}$ of mammary tissue excised ( $n=5$ glands). In study three, pMEC were obtained by removing endogenous parenchyma from six mammary glands from fiveweek old pigs under isoflurane anesthesia using a cleared mammary gland procedure essentially as described [20]. Analgesic (banamine, $2-5 \mathrm{mg} / \mathrm{kg}$ ) was administered postoperatively.

\section{Organoid preparation}

Minced mammary tissue was digested $(1.5 \mathrm{mg} / \mathrm{ml}$ collagenase A (Roche, San Francisco, CA; 75 gg/ml DNase I, Roche; $1 \mathrm{mg} / \mathrm{ml}$ hyaluronidase, MP Biomedicals, Santa Ana, CA) in growth media (10 \% fetal bovine serum [FBS], DMEM/F-12, penicillin G/streptomycin sulfate/ amphotericin B) at $37^{\circ} \mathrm{C}$ for $3 \mathrm{~h}$. Organoids $(40-100 \mu \mathrm{m}$ diameter) were plated in primary porcine mammary epithelial media (modified from MEGM [21] as a 1:1 mix of MCDB170 (US Biological, Salem, MA) and DMEM/F-12 (CellGro, Manassas, VA) with penicillin G/streptomycin sulfate/amphotericin B, $0.5 \%$ FBS, bovine insulin (7.5 $\mu \mathrm{g} / \mathrm{mL}$, Sigma-Aldrich), human EGF $(5 \mathrm{ng} / \mathrm{mL}$, Millipore, Billerica, MA), hydrocortisone $(0.25 \mu \mathrm{g} / \mathrm{mL}$, Sigma-Aldrich), human apo-transferrin $(2.5 \mu \mathrm{g} / \mathrm{mL}$, Sigma-Aldrich), ethanolamine (0.1 mM, Sigma-Aldrich), o-phosphoethanolamine (0.1 mM Sigma-Aldrich), bovine pituitary extract $(35 \mu \mathrm{g} / \mathrm{mL}$, Gemini Bio-Products, West Sacramento, CA), and lipid-rich bovine serum albumin $(0.1 \%$, Gemini Bio-Products).

\section{Cell culture}

Primary pMEC were maintained in porcine mammary epithelial media or growth media, and were differentially trypsinized to reduce the number of contaminating fibroblasts [21]. HEK293FT cells (Invitrogen, Grand Island, NY) were maintained in HEK293FT media (DMEM, 10 \% FBS, penicillin G/streptomycin sulfate, non-essential amino acids and $1 \mathrm{mM}$ sodium pyruvate). $\mathrm{NIH} / 3$ T3 cells (ATCC) were maintained in high glucose DMEM (Hyclone Laboratories, GE Healthcare Life
Sciences, Logan UT) with 10 \% FBS, 10 mM Hepes, $1 \mathrm{mM}$ sodium pyruvate, penicillin G/streptomycin sulfate.

\section{Vectors and virus}

The human elongation factor $1 \alpha(\mathrm{EF} 1 \alpha)$-tdTomato and phosphoglycerate kinase (PGK)-tdTomato plasmids were generated from pLVX-IRES-tdTomato (cytomegalovirus (CMV)-tdTomato; Clontech, Mountain View, CA) by cloning the EF1 $\alpha$ promoter from $\mathrm{pEF} 6 / \mathrm{myc}-\mathrm{His} \mathrm{C}$ (Invitrogen) or the human PGK promoter (GenBank:NG_ 008862.1) from the pMNDU3-PGK-Luc plasmid (UC Davis Vector Core, Sacramento, CA) by PCR (Additional file 1: Figure S1A). The PGK-T antigens (Tag)-CMV-tdTomato construct (Additional file 1: Figure S1B) was generated by first constructing pLVX-PGK-Tag. IRES-tdTomato was excised from pLVX-PGK-tdTomato to give pLVXPGK. The Tag sequences encoding mouse polyomavirus small Tag (ST), middle Tag (MT) and large Tag (LT; GenBank:J02288) were amplified from p53.A6.6 (pPY-1; ATCC, Manassas, VA) and ligated into pLVX-PGK to generate pLVX-PGK-Tag. The CMV promoter was excised from pLVX-IRES-tdTomato and ligated into pLVX-PGKTag to generate pLVX-PGK-Tag-CMV. The tdTomato coding sequence was amplified from pLVX-IREStdTomato and ligated into pLVX-PGK-Tag-CMV to generate pLVX-PGK-Tag-CMV-tdTomato. All constructs were sequence verified.

Lentiviral supernatants for PGK-Tag-CMV-tdTomato were prepared by the University of California San Francisco viral core and titrated by flow cytometry $\left(9.3 \times 10^{7}\right.$ transduction units $[\mathrm{TU}] / \mathrm{ml})$. CMV-tdTomato viral supernatant was produced by triple transfection of HEK293FT cells in Opti-MEM I (Invitrogen) with packaging vector $\left(16 \mu \mathrm{g} / 150 \mathrm{~cm}^{2}\right.$ cells; pCMV-dR8.91, UC Davis Vector Core), envelope vector $\left(3.2 \mu \mathrm{g} / 150 \mathrm{~cm}^{2}\right.$ cells; pMDGVSVG, UC Davis Vector Core) and transfer vector $(16 \mu \mathrm{g} /$ $150 \mathrm{~cm}^{2}$ cells; pLVX-IRES-tdTomato) with Lipofectamine 2000 (Invitrogen). Lentiviral particles were concentrated by $100 \mathrm{kDa}$ cut-off centrifugation (Millipore).

Viral stocks were titrated in HEK293FT cells using qPCR [22]. The woodchuck hepatitis virus posttranscriptional regulatory element (WPRE) was used to measure integration and values normalized to the number of human albumin copies (WPRE Fwd GCGTCTGGAACAATCAAC CT and Rev GGCATTAAAGCAGCGTATCC; hAlbumin [GenBank:152112963] Fwd GTGCTGCCTCGTAGAGTT TTCTG and Rev TCAATAGCCATGTGACCAGTGACT).

\section{Fluorescence activated cell sorting}

Primary pMEC cultures were expanded for 13-14d postisolation with two differential trypsinizations using Accutase (Innovative Cell Technologies, Mira Mesa, CA) to remove fibroblasts, followed by Accumax (Innovative Cell 
Technologies) to dislodge pMEC. Single cells were incubated with phycoerythrin-conjugated anti- CD140a (BD Biosciences, Franklin Lakes, NJ) and/or biotinylated antihuman CD49f (AbD Serotec, Oxford, UK), followed by streptavidin-Alexa 488 (Jackson Immunoresearch) and propidium iodide $(10 \mu \mathrm{g} / \mathrm{ml})$ and sorted using a MoFlo cell sorter (Cytomation, West Lafayette, IN).

\section{Viral transduction in vitro}

Adherent pMEC were transduced overnight using a multiplicity of infection (MOI) of 100 for PGKtdTomato, EF1 $\alpha$-tdTomato or CMV-tdTomato, or an MOI of 20 for PGK-Tag-CMV-tdTomato, along with polybrene $(6 \mu \mathrm{g} / \mathrm{mL}$; Millipore). For study four, cultures of CD140a- pMEC were transduced with PGK-Tag (ss071712), pLVX-PGK-Tag-CMV-tdTomato (ss082112, 27-1, 27-3, 28-3) or CMV-tdTomato (ss071712). Two pMEC lines (ss020513_1, ss020513_2) were sorted to be CD140a-/CD49f + then transduced with PGK-Tag-CMVtdTomato. A subset of CD140a- pMEC transduced with PGK-Tag-CMV-tdTomato were sorted for tdTomato + either $7 d(27-3,28-3)$ or $17 d$ later $(27-1,28-6)$ depending on the initial number of CD140a- pMEC.

\section{Viral transduction in vivo}

In study two, saline or lentivirus (CMV-tdTomato, $5 \times 10^{6}$ TU; EF1 $\alpha$-tdTomato, $1 \times 10^{7}$ TU and PGK-tdTomato, $5 \times$ $10^{6} \mathrm{TU}$ with or without $6 \mu \mathrm{g} / \mathrm{ml}$ polybrene was instilled into the left (with polybrene; one gland/treatment) and right (without polybrene; one gland/treatment) thoracic and abdominal mammary glands of pigs $(n=9)$ via one of the two mammary ducts (intraductal) under isoflurane anesthesia. Additionally, saline or lentivirus suspension with $6 \mu \mathrm{g} / \mathrm{ml}$ polybrene was injected directly into the mammary parenchyma (20-25 $\mathrm{mm}$ subcutaneously; intramammary) in the four remaining mammary glands of each pig (one gland/treatment). Mammary glands were harvested at necropsy 5, 10 or $15 \mathrm{~d}$ later, and snap frozen or fixed in $4 \%$ paraformaldehyde.

\section{Ex vivo transduction and grafting}

In study three, dissociated mammary organoids $(n=30)$ were transduced overnight $(\mathrm{MOI}=100)$ with PGKtdTomato, CMV-tdTomato, EF1 $\alpha$-tdTomato, CMV-Tag, EF1 $\alpha$-Tag, PGK-Tag or no vector (control) with polybrene $(6 \mu \mathrm{g} / \mathrm{ml})$. After $24 \mathrm{~h}(n=4$ pigs $)$ or $8 \mathrm{~d}(\mathrm{n}=6 \mathrm{pigs})$ cultures of organoids were trypsinized and resuspended in serum-free media. Donor pigs were anesthetized with isoflurane and cells reinstilled via two intramammary injections/gland $\left(0.9-4.5 \times 10^{5}\right.$ cells/injection; $n=2$ glands/ construct/pig) and each site closed with Vetbond (3 M, St. Paul, MN). The isografted mammary glands were harvested 3-5 weeks later, minced, and randomly divided for snap freezing in liquid $\mathrm{N}_{2}$ or fixation in $4 \%$ paraformaldehyde.

In study four, lentivirus-transduced pMEC were injected into NSG mice under isoflurane anesthesia. A range of $0.4-1 \times 10^{6}$ pMEC resuspended in $20 \mu \mathrm{L}$ of HyStem-C hydrogel ( $n=46$ injected sites; Glycosan Biosystems, Alameda, CA) or Matrigel HC $(n=24$ injected sites; BD Biosciences) was injected either subcutaneously or directly into the mammary gland. For instillation of cells into the mammary gland, a small skin incision $(\sim 5 \mathrm{~mm})$ was made to visualize accurate placement within the mammary fat pad. Mice were treated postoperatively with a single dose of analgesic (buprenorphine; $0.05 \mathrm{mg} / \mathrm{kg}$ ) and were monitored once daily over $7 \mathrm{~d}$ for changes in health and behavior. Table 1 summarizes the mice and cell injections used.

\section{In vitro assays}

Cell number was assayed using a methylene blue assay [23]. Cells were plated in 96 well-plates at 2000 cells/well $(n=6 /$ cell line $)$ on d0, and medium changed every $2 \mathrm{~d}$.

Cells $(20,000 /$ well $)$ were resuspended in $0.35 \%$ agar in growth medium and poured onto a base layer $(0.7 \%$ agar in growth media), with growth medium changed every $2 \mathrm{~d}$. After $21 \mathrm{~d}$, cells were stained $(0.04 \%$ crystal violet, $2.1 \%$ citric acid), imaged and colonies $>50 \mu \mathrm{m}$ counted using ImageJ (NIH; http://rsb.info.nih.gov/ij/).

\section{Mammary gland and tumor whole mounts}

Semi-thick tissue sections were dehydrated through graded ethanols to xylene (study three) or graded glycerol (study four) as described [24]. Sections were imaged using a fluorescent dissecting microscope. The percent red area was calculated using Image J. Regions positive for red fluorescence were dissected and processed to paraffin for hematoxylin and eosin staining (H\&E) and immunohistochemistry. Regions having dense ductal structures (study three, PGK-Tag mammary glands) were microdissected, paraffin-embedded and sectioned for histology (H\&E) and genomic DNA extraction.

\section{Western blotting}

Cells $\left(1-3 \times 10^{6}\right)$ were lysed and sonicated in buffer with protease and phosphatase inhibitors, and western blots performed as described [25]. Antibodies were from Santa Cruz Biotechnology (rat polyomavirus early, cyclin D1, and p53), Cell Signaling Technology (Rb, phospho Rb, MAPK1/3 and phospho MAPK1/3)) and Jackson ImmunoResearch (HRP-conjugated secondary antibodies). 


\section{Genomic DNA extraction and PCR detection of integration}

Genomic DNA was extracted from paraffin-embedded tissues as described [26] using combined heating and non-heating protocols. DNA quality was assessed using primers for the porcine prolactin receptor gene [27]. The incidence of lentiviral integration in studies two and three was determined using primer sets specific to tdTomato (Clontech; tdTomatoFin Fwd CTCCGAGGACAACAACATGG and Rev CTTGGTCACCTTCAGCTTGG; CMVtdTomato Fwd AACACGATGATAATATGGTGA GCAAGGG and TdTomatointernal Rev GACAGCTT CTTGTAATCGGGGATGTC) or amplified a product specific for PGK-Tag (PGKTagspec5P TGAAGATGTA AAGGGTCAAATAGC and PGKspec3P-2 AAGGCATT AAAGCAGCGTATC).

\section{$R T-q P C R$ and $q P C R$ (study two)}

Total RNA was extracted and reverse transcribed as described [28]. Primers spanned across exons of LEF1 (Fwd GACGAGCACTTTTCTCCAGGA, Rev TAATCTGTCC AACACCACCCG [GenBank:XM_005666939]), cyclin D1, (Fwd CCCTCCGTGTCCTACTTCAA, Rev CAGGCGGC TCTTTTTCAC [GenBank:AK400348)], cyclin A2, (Fwd TTGTGGGCACTGCTGCTATG, Rev GCAAGGACTTT CAAAACGAGGTG [GenBank:GQ265874]), MYC, (Fwd CGCTTTTTGGACGCTGGATT, Rev TTCTCCTCCTC GTCGCAGTA [GenBank:X97040]), RB1 (Rb), (Fwd ACG CCAACAAAAATGACTCC, Rev GTTGCCTCCTTCAG CACTTC [GenBank: JX099502]), TP53 (p53), (Fwd CC ATCCTCACCATCATCACACT, Rev CTCTGTGCGGC GGTCTCT [GenBank:NM_213824]), P21, (Fwd GCAGA CCAGCATGACAGATT, Rev TGTTTCCAGCAGGACA AGG [GenBank:XM 001929558]), P16, (Fwd GAGGGC TTCCTGGACACTTTG, Rev TGCAGTATCTCTGGG TTTCAATGA; [GenBank:AJ316067]) and 18S ribosomal RNA, (Fwd ACGGCTACCACATCCAAGGA, Rev CCA ATTACAGGGCCTCGAAA [GenBank: AF179868]). All PCR products were sequenced. RT-qPCR was as described [28], where relative transcript abundance was calculated using a 5-point standard curve obtained by 5 -fold serial dilutions of a pMEC complementary DNA pool. The average relative expression for each sample was normalized to $18 \mathrm{~S}$ ribosomal RNA levels [29].

DNA was purified from tissues homogenized in TriReagent (Molecular Research Center, Inc, Cincinnati, Ohio). Genomic DNA (40 ng) was amplified with tdTomatoFin primers using qPCR [28]. Standard curves were generated from genomic DNA extracted from mouse mammary tumor cells (SSM-2) transduced with EF1 $\alpha$ tdTomato lentivirus and selected for tdTomato expression using a MoFlo cell sorter. The relative number of integrated virus particles was normalized to the corresponding level of $18 \mathrm{~S}$ ribosomal DNA as a loading control for gene copy number (Fwd ACGGCTACCA CATCCAAGGA, Rev CCAATTACAGGGCCTCGAAA [Genbank: NR_046261]).

\section{Immunohistochemistry}

Slides were prepared as described [28], with modifications. Sections were incubated with anti-dsRED (1:50; Clontech), anti-human progesterone receptor (1:50; DakoCytomation, Carpinteria, CA), anti-human estrogen receptor (clone 6 F11, ThermoFisher Scientific, Waltham, MA), anti-vimentin (1:100; Millipore), anti-bovine cytokeratin 8/ 18 (1:2000; Fitzgerald Industries, Acton, MA), or anti-Ki67 (clone Ab-4; 1:1000; ThermoFisher Scientific) in $5 \%$ horse serum in PBS at $4{ }^{\circ} \mathrm{C}$ overnight and detected with NovaRED (Vector Laboratories) or DAB (Invitrogen).

\section{Statistics}

Differences were assessed by two-way ANOVA, and $P$ values calculated using Students $t$-tests. Data is presented as means $\pm \mathrm{SEM}$, with significance at $P<0.05$. For animal studies, individual mammary glands were treated as the experimental unit. Animal group sizes were selected to provide $>80 \%$ power to detect differences, taking into consideration our experience with assessing porcine mammary gland morphology [29] and the typical engraftment characteristics and rates of primary bovine and human MEC in immunodeficient mice [30, 31].

\section{Results}

\section{Primary culture of porcine mammary cells}

Dissociation of mammary tissue from nulliparous pigs (study one) yielded epithelial organoids that adhered to plastic within $24 \mathrm{~h}$ (Fig. 1). At 2d post-dissociation, mixed populations of cells included a cytokeratinpositive epithelial population (luminal), cells positive for both cytokeratin and vimentin (basal/myoepithelial) and

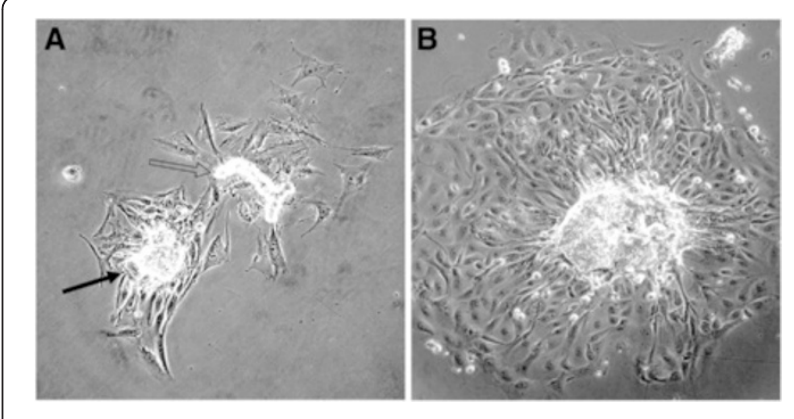

Fig. 1 Representative images of pig mammary organoids collected after enzymatic dissociation of mammary gland tissue from a nonpregnant female. a A cluster of epithelial cells (closed arrowhead) and piece of duct (open arrowhead) with surrounding outgrowth $24 \mathrm{~h}$ after dissociation and plating. b An organoid with typical outgrowth $48 \mathrm{~h}$ after dissociation. Scale bar $=100 \mu \mathrm{m}$ 
two morphologically distinct vimentin-positive populations, one most likely being fibroblasts (Fig. 2).

\section{Lentivirus for manipulating $\mathrm{PMEC}$ in vitro and in vivo}

We compared the CMV, EF1 $\alpha$ and PGK promoters in lentivirus-transduced pMEC (study one), and determined EF1 $\alpha$ to be the most effective in vitro (Additional file 2: Figure S2B). We next determined which promoter was most effective for pMEC in vivo, and the best route (intraductal or intramammary) for introducing lentivirus into the mammary gland (study two). Analysis of genomic DNA revealed that polybrene increased the incorporation of lentivirus instilled intraductally by 24fold (Fig. 3a; $P<0.05$ ). We detected tdTomato in $5 / 9$ CMV-, 5/9 EF1 $\alpha$ - and in 4/9 PGK-tdTomato glands injected intraductally with lentivirus (Fig. 3b). In mammary glands receiving intramammary injections of lentivirus with polybrene we detected tdTomato in $2 / 8$ CMV-, in 4/8 EF1 $\alpha$ - and in 5/9 PGK-tdTomato glands (Fig. 3c). Glands transduced by intraductal instillation were analyzed for ductal outgrowths expressing tdTomato (Additional file 3: Figure S3). Clustered tdTomato-positive structures were present in the mammary gland injected with either EF1 $\alpha$-tdTomato or CMV-tdTomato lentivirus, consistent with localized transduction.

We examined whether pMEC transduced ex vivo would develop into epithelial structures upon transplantation into donor pigs (study three). Expansion of cells for $8 \mathrm{~d}$ post-transduction before reinstallation yielded fluorescent TDLU outgrowths from EF1 $\alpha$-tdTomato
( $n=1$ of 8 mammary glands) and CMV-tdTomato ( $n=2$ of 8) transduced cells (Fig. 4a), but not from PGKtdTomato transductants or in control glands (not shown), despite detection of tdTomato in 2/6 glands transplanted with PGK-tdTomato pMEC (Fig. 4b). Expansion of cells for $24 \mathrm{~h}$ post-transduction prior to reinstallation led to detection of genomic tdTomato in $>50 \%$ of glands injected with CMV-tdTomato pMEC, EF1 $\alpha$-tdTomato or PGKtdTomato transduced cells (Fig. 4c).

\section{Oncogene-induced pMEC transformation in vitro}

We compared the efficacy of the three promoters for expressing the Tag oncoproteins ST, MT and LT produced by splicing of the murine polyomavirus Tag. Based on the number of colonies in soft agar, the PGK promoter was most effective for directing Tag-induced transformation of pMEC in vitro (Additional file 4: Figure S4). When pMEC transduced with PGK-Tag, CMV-Tag or EF1 $\alpha$-Tag were injected as isografts, we only detected dense structures in whole mounts from all PGK-Tag engrafted glands that were evaluated (Fig. 5a; 2 pigs, 4 mammary glands total). These structures histologically resembled TDLU (Figs. 5b and c), and were positive for the expression of estrogen receptor (Additional file 5: Figure S5A), progesterone receptor (Additional file 5: Figure S5B), and epithelial cytokeratins (Additional file 5: Figure S5D) and negative for vimentin (Additional file 5: Figure S5C). Areas within and surrounding the TDLU were confirmed to be PGK-Tag positive (Fig. 5d). Subsequent experiments involving Tag utilized the PGK promoter.

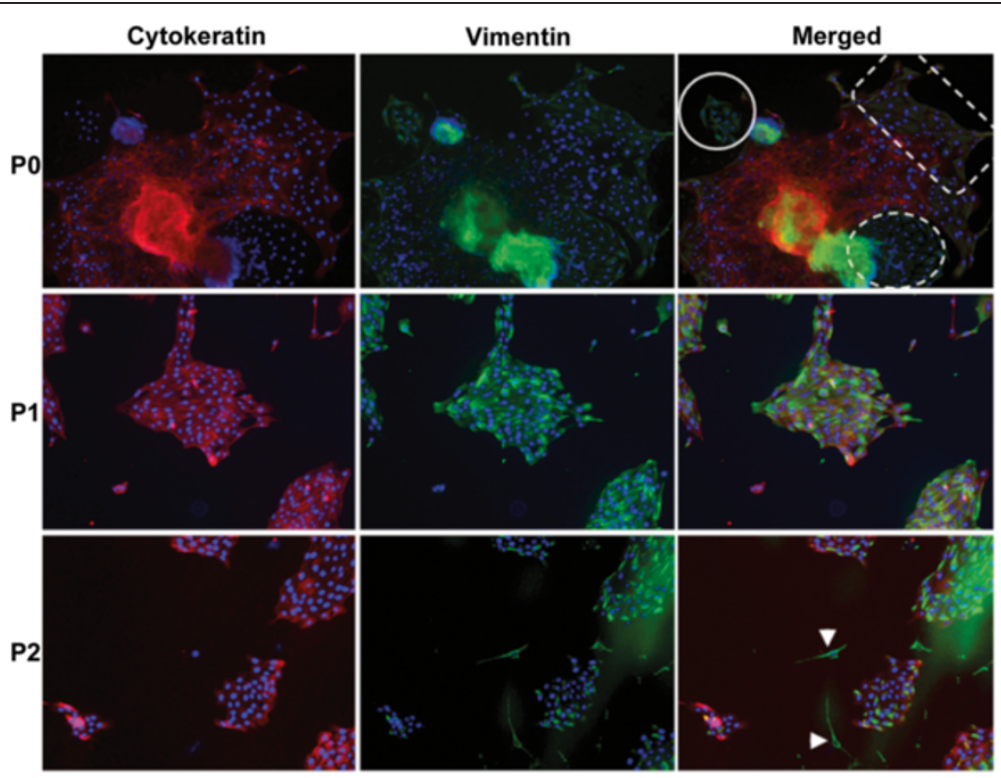

Fig. 2 Representative fluorescence images from pig mammary organoids $48 \mathrm{~h}$ after dissociation (P0) and after passages 1 and 2 (P1 and P2). Four distinct populations of cells were visible at P0. Cytokeratin-positive luminal epithelial cells, vimentin-positive fibroblasts (dashed circle, arrowheads in P2), cells positive for both vimentin and cytokeratin (dashed rectangle) and small, vimentin- positive cells (solid circle) found infrequently only at $\mathrm{PO}$ 


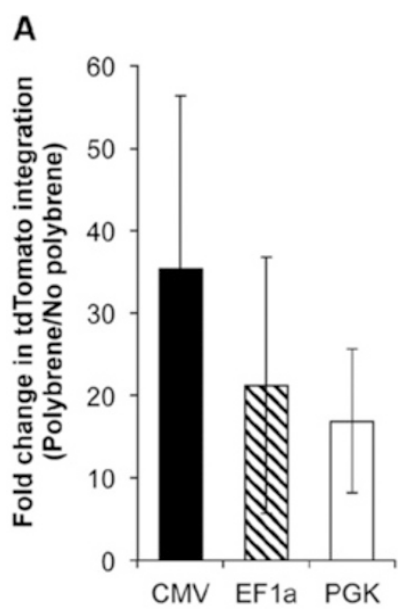

B
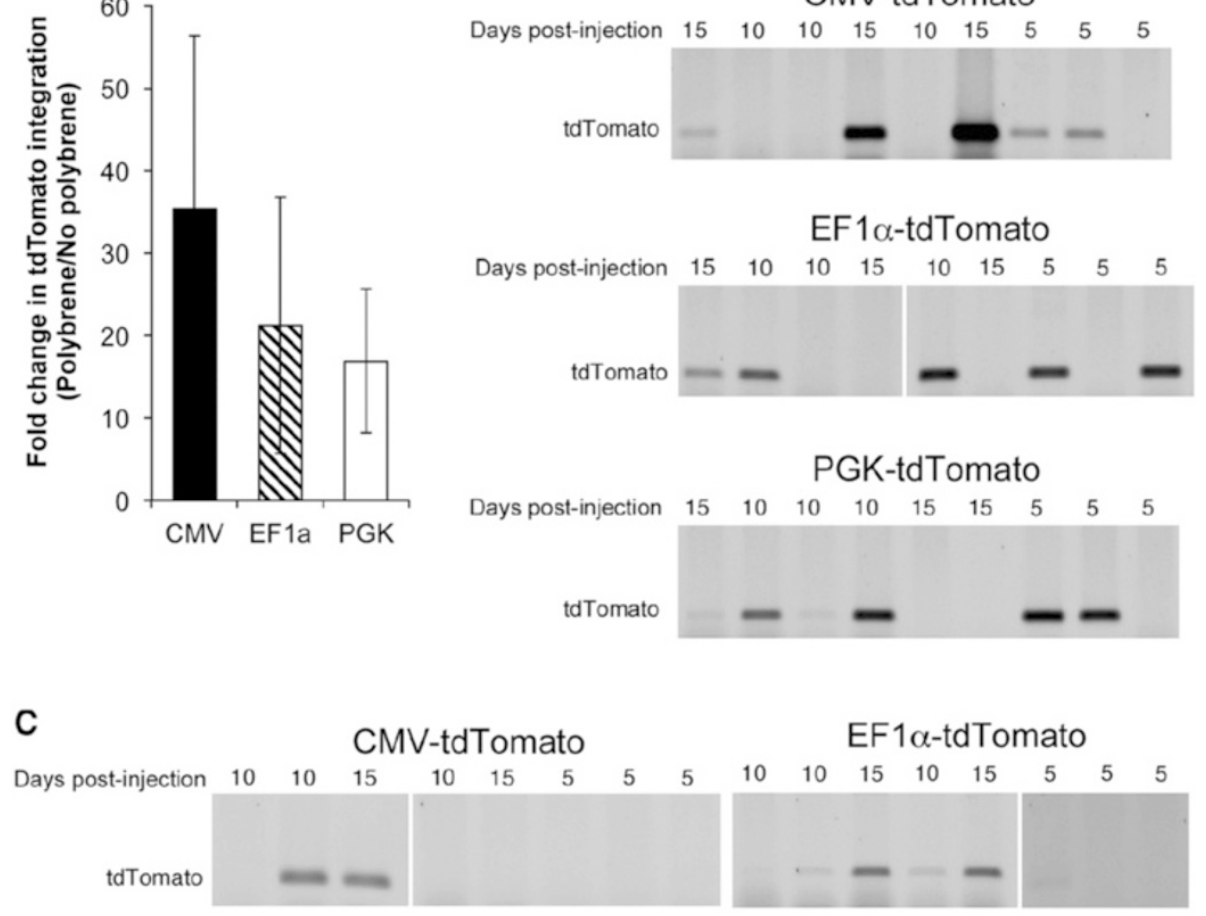

PGK-tdTomato

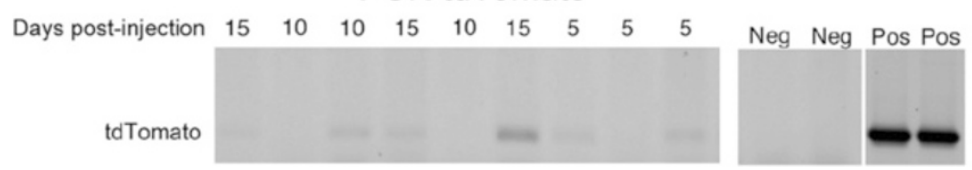

Fig. 3 Injection of lentivirus into the pig mammary gland. a Glands were injected intraductally ( $n=9$ pigs) with CMV-tdTomato, EF1atdTomato or PGK-tdTomato lentivirus with or without polybrene and harvested 5, 10 or 15d later. Lentiviral integration was determined by qPCR for tdTomato, corrected for $18 \mathrm{~S}$ ribosomal RNA levels and expressed as a ratio of tdTomato integration with or without polybrene. Data are means \pm SEM $(n=6-7)$. b Glands were injected intraductally ( $n=9$ pigs) with CMV-tdTomato, EF1a-tdTomato or PGK-tdTomato lentivirus and polybrene and harvested 5, 10 or $15 \mathrm{~d}$ later. c Injections were into the mammary parenchyma ( $n=9$ pigs) with CMV-tdTomato, EF1atdTomato or PGK-tdTomato lentivirus and polybrene and harvested 5, 10 or 15d later. Negative controls (Neg) are genomic DNA from the mammary glands of two untreated pigs. Positive controls (Pos) are two pMEC lines transduced with CMV-tdTomato

We next profiled Tag-induced molecular changes in pMEC. Those pMEC ( $n=4$ pigs) transduced with PGKTag exhibited increased proliferation and anchorageindependent growth (Figs. 6a-b). Analysis of the expression of oncogenes (LEF-1, cyclin A2, cyclin D1, myc) and tumor suppressor genes (p16, p21, Rb and p53) revealed that Tagtransduced pMEC had elevated P16 $(P=0.01)$ and cyclin A2 mRNA expression $(P=0.03$; Fig. $6 \mathrm{c})$. The LT protein was detected in PGK-Tag transduced pMEC (Fig. 7a), with upregulated TP53 $(P=0.007)$ and decreased phosphorylated $\mathrm{Rb}(P=0.01$; Figs. $7 \mathrm{c}-\mathrm{d})$ and a tendency for increased phosphorylated MAPK1/3 ( $P=0.13$; Fig. $7 \mathrm{~b})$. We also refined our transduction protocol using a vector that coexpressed tdTomato with Tag (PGK-Tag-CMV-tdTomato). We found that $55 \pm 7 \%$ pMEC transduced by PGK-
Tag-CMV-tdTomato were red $7 \mathrm{~d}$ after transduction whereas $95 \pm 0.5 \%$ were positive for tdTomato 4 weeks post-transduction (not shown).

\section{FACS sorting of primary PMEC}

We separated pMEC using lineage-specific markers previously used for human and mouse MEC [32]. Stromal cells were removed by sorting for CD140a. The remaining pMEC were sorted as CD49f + and CD49fthat comprised $79 \%$ and $21 \%$, respectively $(P<0.001)$. The CD140a-CD49f- cells were enriched for cytokeratinpositive and vimentin-negative cells (luminal-like) whereas CD140a-CD49f + subpopulations were enriched for cytokeratin- and vimentin-positive cells (basal-like) (Additional file 6: Figure S6). Few cytokeratin-negative and vimentin- 


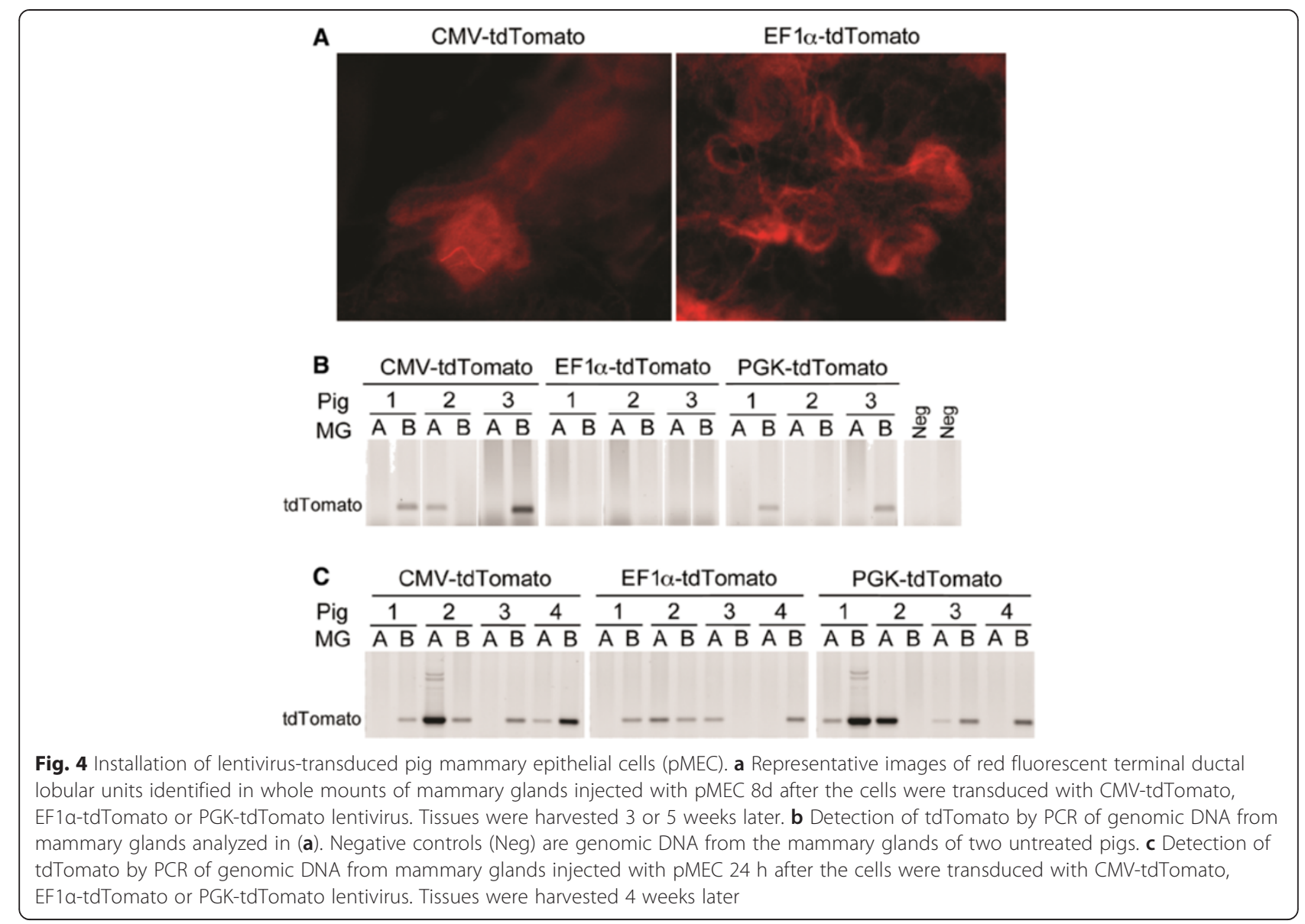

positive cells were present in CD140a ${ }^{-}$CD49f + populations (0.07 \% +/- 0.03, second passage)

Dissociated pMEC depleted for CD140a (CD140a-, $n=5$; Table 1) and enriched for CD49f (CD140a-CD49f $+n=2$; Table 1) were transduced with PGK-Tag-CMV-tdTomato, and some further enriched for tdTomato (CD140atdTomato+; $n=3$; Table 1). Cells sorted for CD140atdTomato + exhibited red fluorescence in vitro (Additional file 7: Figure S7A). Transduction by PGK-Tag-CMVtdTomato yielded transformed pMEC that gave rise to colonies able to grow in soft agar (Figure S7B) expressing ST, MT and LT (not shown).

Populations of pMEC transduced by PGK-TagCMV-tdTomato varied morphologically in vitro. While CD140a-CD49f + pMEC retained a cobblestone morphology (Additional file 8: Figure S8A), CD140a ${ }^{-}$tdTomato ${ }^{+}$pMEC were elongated (Additional file 8: Figure S8B), developed foci (Additional file 8: Figure S8C) or maintained a cobblestone morphology without foci (Additional file 8: Figure S8D).

\section{Transformed xenografted pMEC generate orthotopic and ectopic tumors}

To determine the tumorigenicity of transformed pMEC, all cell lines were injected into NSG mice either subcutaenously with hydrogel or Matrigel, or into the mammary fat pads. Cells injected in the fat pad, either in Matrigel or hydrogel, failed to form tumors after 36 weeks $(n=5$; Table 1$)$. There were striking differences among tumors that formed subcutaneously following coinjection with Matrigel or hydrogel. While all transformed pMEC in Matrigel developed tumors ( $>1 \mathrm{~mm}$ ) after 4 weeks, only one line in hydrogel developed tumors after 16 weeks (Table 1 ).

Tumors from CD140a CD49f + PGK-Tag-CMV-tdTomato pMEC injected with Matrigel or hydrogel were 54-74\% positive for red fluorescence (Additional file 9: Figure S9A-B). Tumors comprised mixed neoplastic glandular epithelium and nests of squamous epithelium having intracellular bridges and dyskeratosis with occasional microcalcifications and dense fibrosis (Fig. 8a-d). Immunohistochemistry for cytokeratin 8/18, Ki-67 and nuclear hormone receptors confirmed these tumors were epithelial and proliferative (Figs. 8e-f), albeit negative for estrogen receptor (Fig. 8g) and progesterone receptor (not shown). Tumors arising from CD140a- PGK-TagCMV-tdTomato pMEC co-injected subcutaneously with Matrigel were $<50 \%$ red (Additional file 9: Figure S9E) and contained occasional nests of squamous epithelium 

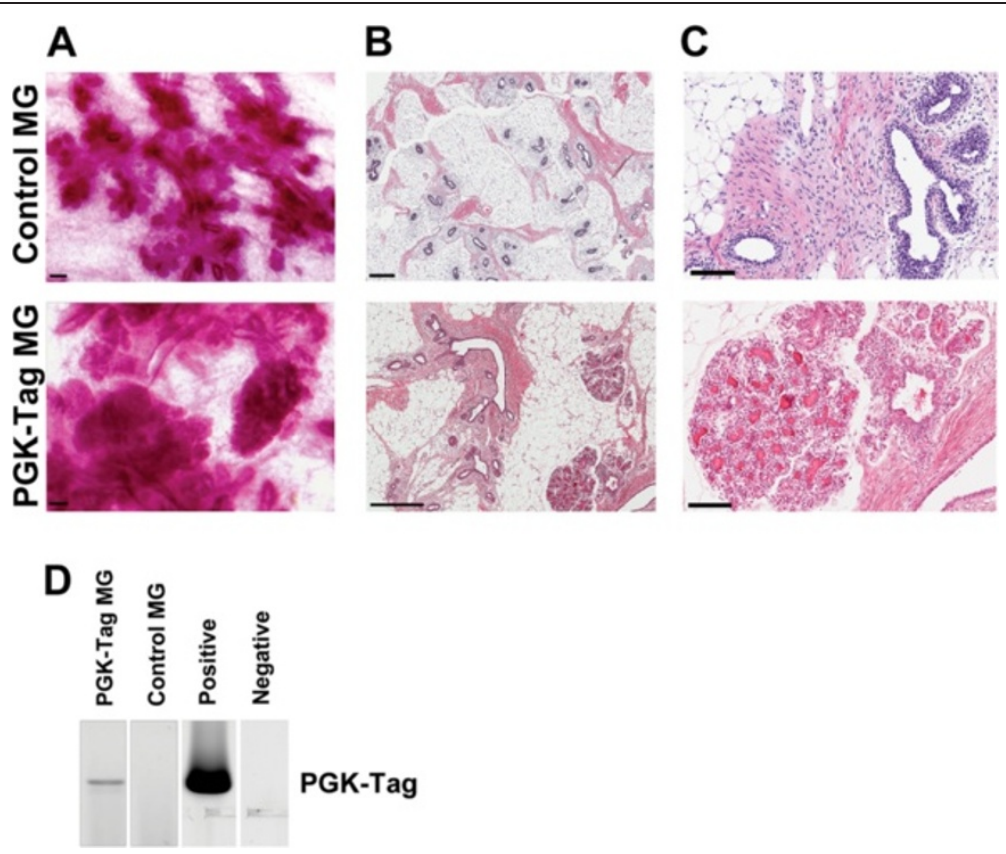

Fig. 5 PGK-Tag transformed PMEC promote the precocious development of dense epithelial structures that resemble terminal ductal lobular units (TDLU). a Whole mounts of mammary glands injected with either pMEC transduced with PGK-Tag lentivirus or non-transduced pMEC (control mammary gland). $\mathbf{b}$ Densely packed structures identified by whole mount analysis of PGK-Tag engrafted mammary glands were sectioned and stained (H\&E). A parenchyma-rich area from a contralateral control mammary gland is included for comparison. Scale bar $=100 \mu \mathrm{m}$. c Magnification of H\&E from (a) scale bar $=100 \mu \mathrm{m}$. d PCR detection of PGK-Tag in genomic DNA from paraffin sections of the mammary gland shown in (b). Positive control is genomic DNA from pMEC transduced with PGK-Tag. Negative is $\mathrm{ddH}_{2} \mathrm{O}$ template

mixed with glandular epithelium (Fig. 8h-i). Whole mount analysis revealed red fluorescent growths in the mammary fat pads of mice carrying CD140a- pMEC in Matrigel (6/8 injections; Additional file 9: Figure S9D) that were subsequently found to comprise nonneoplastic ducts or cysts (Fig. 8f), similar to results for normal human and bovine MEC transplanted into the mouse mammary fat pad [31, 30].

We recorded variation among growths arising from CD140- pMEC instilled with hydrogel. One line of transformed pMEC only yielded microscopic fluorescent growths (Additional file 9: Figure S9E), which contained fibrosis and neoplastic squamous epithelial cells (Fig. 8j-k). A second line developed palpable mammary and subcutaneous tumors that were comprised chiefly of fibrous connective tissue. Accordingly, these tumors were strongly vimentin-positive with only scant dsRED immunoreactivity (not shown). A third line of CD140a-tdTomato + pMEC injected in hydrogel infrequently developed tumors in the mammary fat pad (1/8 injections; not shown) that comprised non-neoplastic ducts (not shown) similar to those found for pMEC co-instilled with Matrigel (Fig. 8h).

\section{Discussion}

Here we report the first successful lentivirus-mediated transgenesis and transformation of primary pMEC in vitro and in vivo. Given significant structural and functional similarities between the mammary glands of pigs and humans [9], our approach is a first step toward a promising animal model in which to investigate the tissue-level cellular and environmental interactions behind human breast development and oncogenesis.

A variety of genetically-engineered mouse models has enabled the identification of various genes involved in mammary cancer initiation and progression, yet the resulting tumors often differ in their pathology compared to human breast cancers [33]. This discordance may reflect the greater frequency at which mouse tumors develop from alveolar structures [33] compared to those of the human breast that often arise from less-differentiated TDLU-1 and -2 [17]. As such, investigations into the initiation and progression of tumors within TDLU have been hampered by the absence of similar structures in the mouse mammary gland alongside the challenges associated with obtaining human tissues. Development of a pig breast cancer preclinical model stands to complement recent advances to optimize the limitations of mouse models such as the addition of human stromal elements to the mouse mammary fat pad [34] and reconstitution of the mouse mammary epithelium with human preneoplastic cells [35].

Our techniques enable transformation of MEC derived from the TDLU of pre- and peripubescent pigs that are 


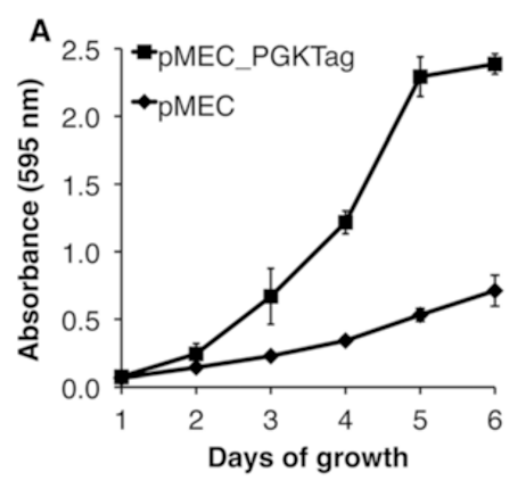

B
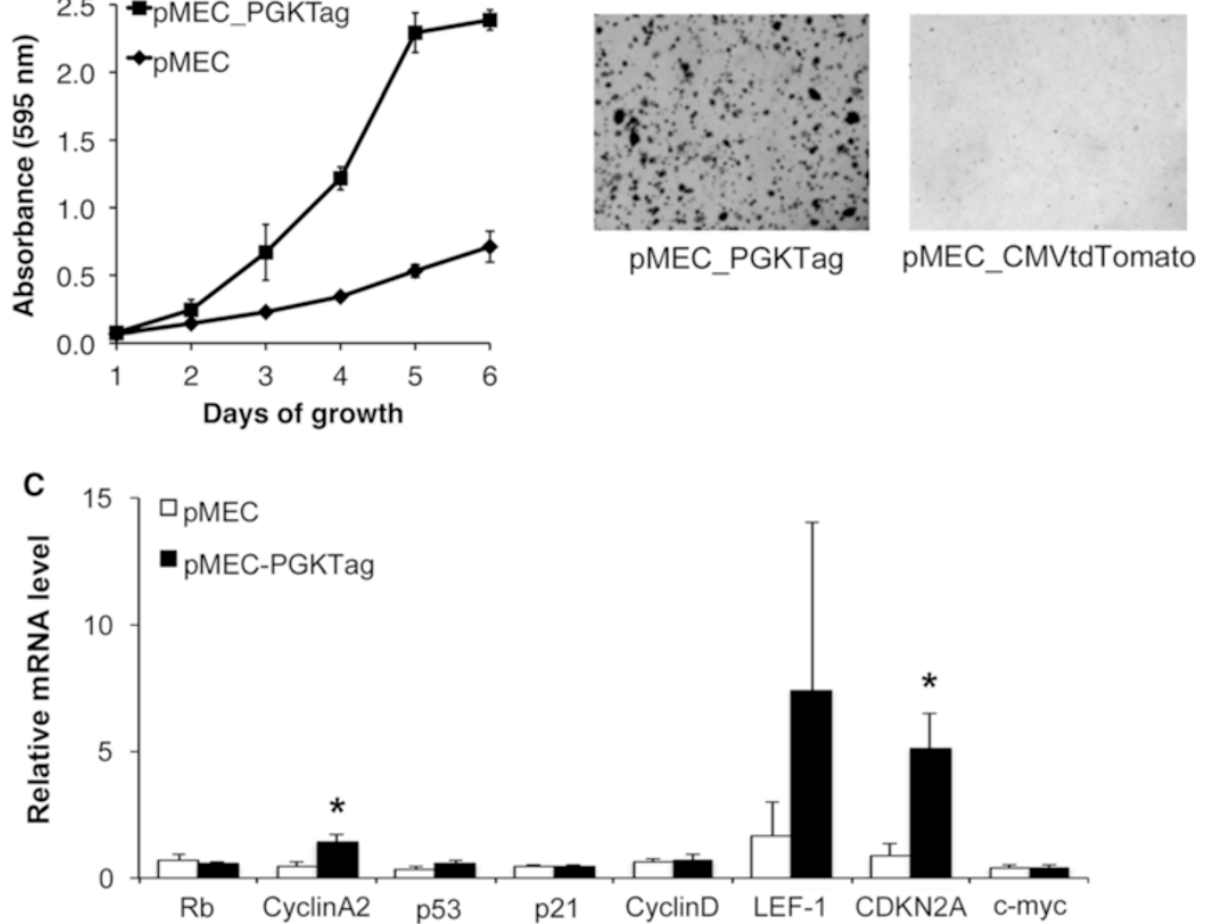

Fig. 6 Pig mammary epithelial cells (PMEC) transduced with PGK-Tag lentivirus exhibit a transformed phenotype. a Growth of pMEC transduced with PGK-Tag $(n=4)$ and control pMEC transduced with CMV-tdTomato $(n=3)$. b Representative image of PGK-Tag transduced pMEC in soft agar. PGK-Tag pMEC formed $753.3 \pm 30$ colonies/well while CMV-tdTomato pMEC yielded no colonies. c pMEC transduced with PGK-Tag $(n=4)$ or PGKTag-CMV-tdTomato $(n=1)$ had similar expression of cyclin D1, myc, p53 and Rb and increased expression of cyclin A2 and p16 $\left({ }^{*} P<0.05\right)$ compared to control pMEC

synonymous with TDLU-1 and -2 in the human breast [9]. Moreover, vacuum-assisted mammary biopsies [19], which are impractical in rodents [36], will allow serial sampling of a pig model of breast cancer to study the response to cancer treatment over time, or the influence of environmental and lifestyle factors on breast cancer risk. While a porcine pre-clinical model has limitations including increased cost and housing requirements [36], these drawbacks are countered by the potential ability to authentically model normal human breast development and breast cancers within a context that is biologically and physiologically more similar to the human.

The human breast and pig mammary gland have a similarly complex stromal microenvironment, which contrasts to that of the rodent mammary gland [18]. Our results highlight the influence of stromal factors on the occurrence and rate of pMEC tumor formation in vivo. Similar to transformed human breast epithelial cells [37], transformed pMEC failed to form tumors in the microenvironment of the mouse mammary fat pad despite developing tumors ectopically. Our data corroborates previous evidence showing that elements of the mouse mammary fat pad are inadequate to support proliferation of non-native epithelium [18]. These data, alongside work by others [34, 31, 30], adds to evidence highlighting differences between species in the stromadirected behavior of the mammary epithelium. Indeed, attempts to reconstruct human [31] or bovine [30] mammary tissues in the mouse mammary fat pad by xenografting tissue fragments or dissociated MEC failed to generate species-specific TDLU.

Given that the pig mammary gland is rich in connective tissues, co-inoculating irradiated pig stromal fibroblasts with transformed pMEC may have increased their viability when xenografted into the mouse mammary fat pad, as for human and bovine MEC [34, 38]. Along these same lines, Matrigel promoted transformed pMEC to form tumors, consistent with the stromal requirements of xenografts of human breast cancer cells [39]. The matrix proteins found in Matrigel can support the growth of cells in a foreign environment, recapitulating the connective-tissue rich stroma of the human breast and pig mammary gland [18, 40]. However, unlike in humans, mammary carcinomas are extremely rare in pigs [41]. This low incidence may reflect innate repressive effects of the stroma, which can restrain the 


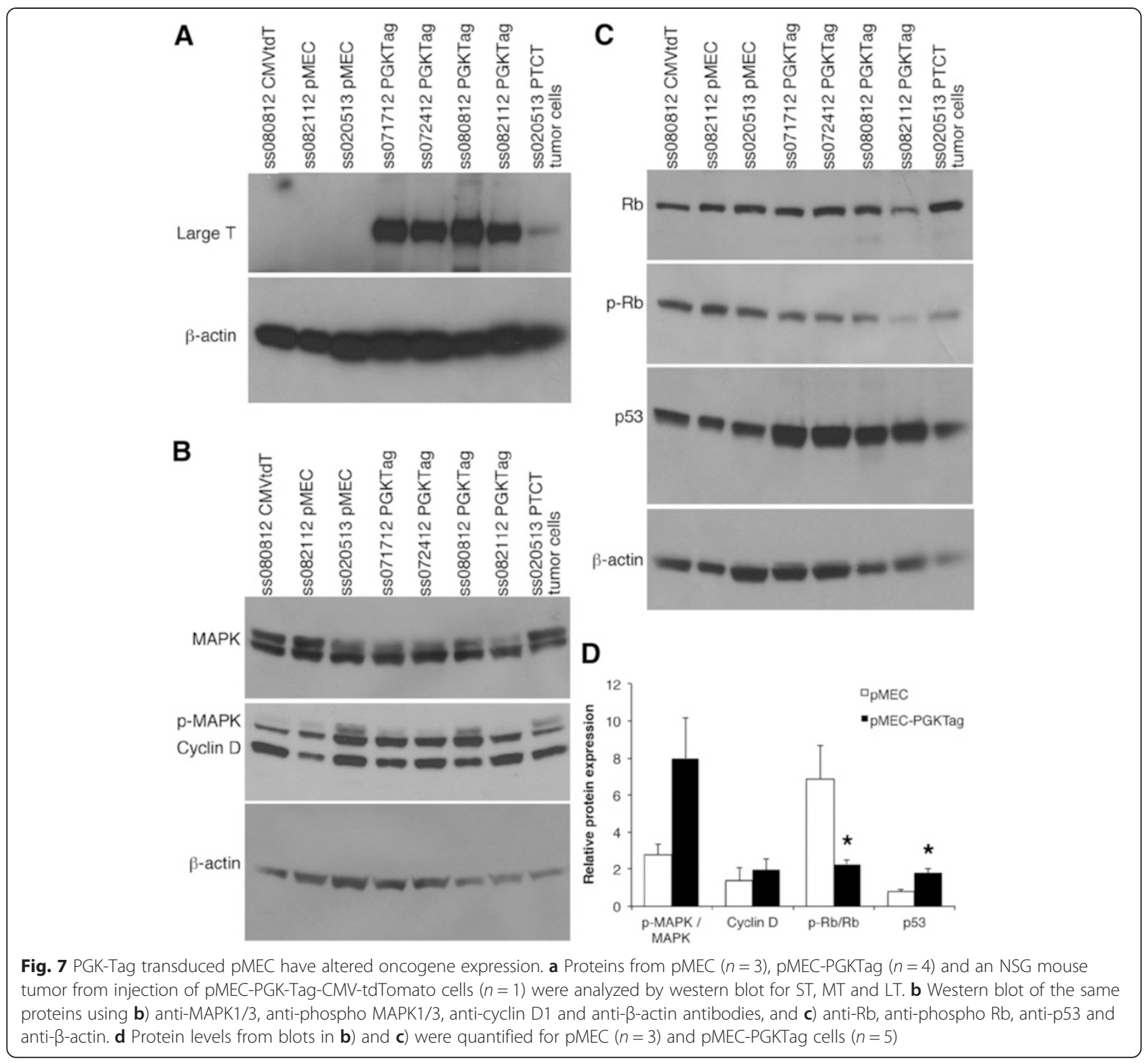

tumorigenicity of undifferentiated mouse embryonic carcinoma cells [42] and prevents marginally abnormal human mammary organoids developing hyperplasias in humanized mouse mammary fat pads [34]. The structure and morphology of tumor stroma associated with xenografts differs from normal stroma [43], suggesting that changes within tumor stroma may be more permissive. Accordingly, transformed porcine dermal fibroblasts readily formed undifferentiated sarcomas in the mammary glands of immunosuppressed pigs [44], while we found that isogenic transplanted pMEC transformed by Tag failed to form palpable tumors in immunocompetent pigs (data not shown). While immunosuppression may have increased the take of transformed pMEC [44], it is also possible that transformation of stromal cells is also required to induce mammary carcinomas in pigs. As such, future work to overcome these repressive mechanisms and develop the pig as an authentic breast cancer model may open up hitherto unexplored mechanisms to defeat breast cancer.

We transformed pMEC by lentivirus-mediated expression of murine Tag proteins. While Tag or similar viral oncoproteins have not been directly implicated in human breast carcinogenesis, Tag activates various oncogenes and bypasses $\mathrm{p} 53$ and $\mathrm{Rb}[45,46]$ as in many human breast cancers $[47,48]$. Mammary tumors that develop from germline transgenic MT expression in the mouse mimic invasive human breast carcinomas 


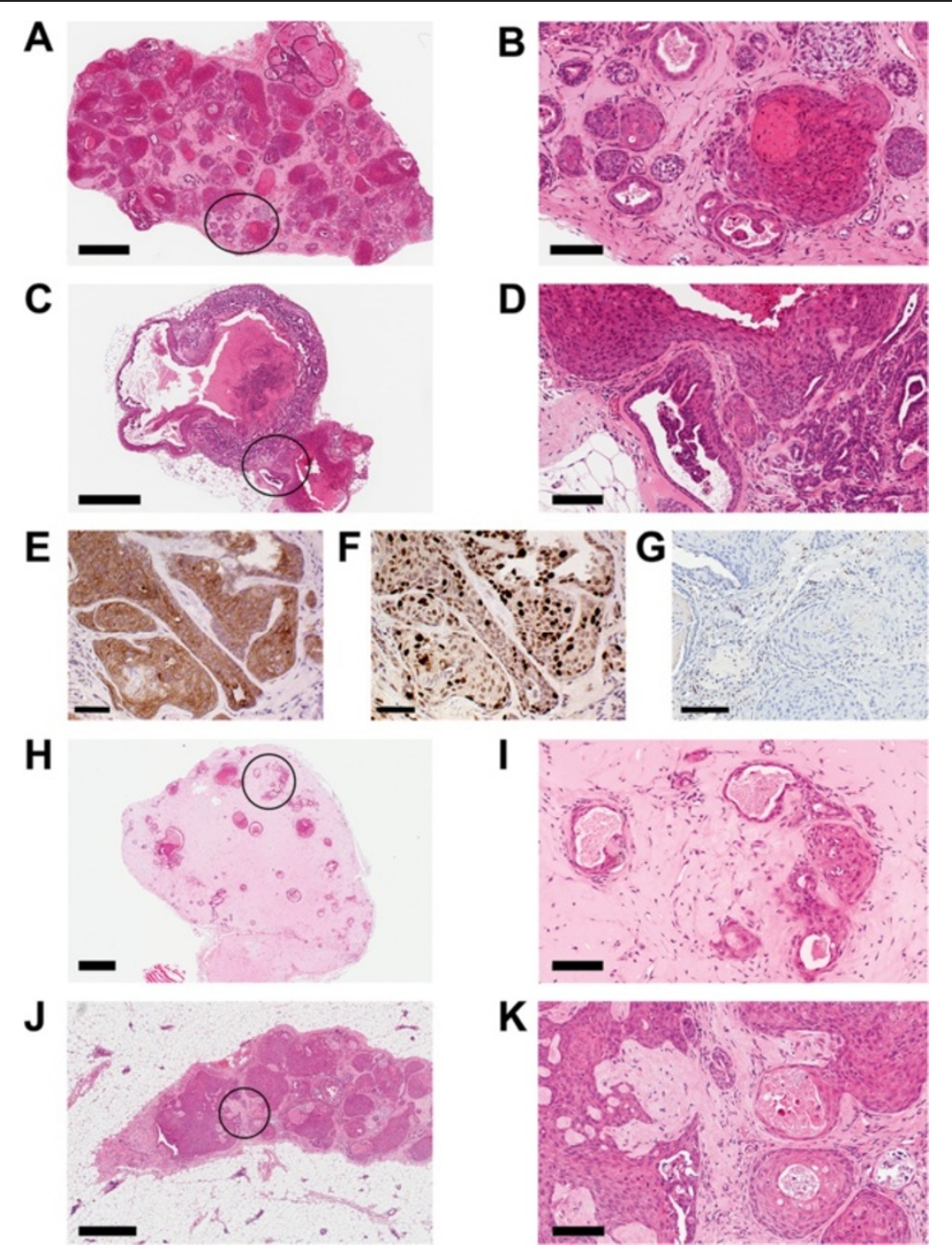

Fig. 8 Xenografted CD140-CD49+ pMEC transduced with PGK-Tag-CMV-tdTomato injected subcutaneously with Matrigel or hydrogel produce epithelial neoplasms. a Section (H\&E) from a CD140-CD49+ PGK-Tag-CMV-tdTomato tumor in Matrigel showing neoplastic glandular epithelium. Scale bar $=600 \mu \mathrm{m}$. b Magnified encircled area in (a). Scale bar $=100 \mu \mathrm{m}$. c Section (H\&E) from a CD140-CD49+ PGK-Tag-CMV-tdTomato tumor in hydrogel showing neoplastic glandular epithelium. Scale bar $=600 \mu \mathrm{m}$. d Magnified encircled area in (c). Scale bar $=100 \mu \mathrm{m}$. Immunolocalization of (e) cytokeratins 8/18, (f) Ki67 and (g) estrogen receptor in CD140-CD49+ PGK-Tag-CMV-tdTomato tumorous pMEC injected with Matrigel. Scale bar $=100 \mu \mathrm{m}$. h CD140- pMEC transduced with PGK-Tag-CMV-tdTomato develop ductal-like structures as subcutaneous xenografts. Section (H\&E) depicting scattered glandular epithelium with hollow or cell-filled lumens. Scale bar $=600 \mu \mathrm{m}$. i Magnified encircled area in (h). Scale bar $=100 \mu \mathrm{m}$. j CD140-tdTomato + pMEC transduced with PGK-Tag-CMV-tdTomato produce epithelial-type neoplasms in mammary fat pads. Section (H\&E) depicting fibrosis with neoplastic squamous epithelium. Scale bar $=600 \mu \mathrm{m}$. k Magnified encircled area in (j). Scale bar $=100 \mu \mathrm{m}$

with progressive loss of ER coincident with increased invasiveness [49]. Herein, Tag-transformed pMEC developed estrogen receptor- negative, proliferative tumors when xenografted to mice. Interestingly, pMEC co-injected with Matrigel into estrogen-treated mice displayed a shorter latency to tumor formation, raising the possibility that transformed pMEC may have initially been hormone-sensitive. Given that mice carrying pMEC co-injected with hydrogel were not treated with estrogen, we cannot ascribe any differences in tumor formation rates to hormone supplementation. Nevertheless, our observations are consistent with similar findings in a mouse explant model of transgenic MT [50].

Previous reports indicate that primary human MEC require disruption of multiple pathways for complete transformation [37, 51, 35] whereas rodent cells can be transformed by two oncogenes [52]. Along these lines, primary pig fibroblasts [44] and human breast epithelial cells [51] were transformed by sequential transduction with dominant negative p53, activated CYCLINdependent kinase complex (Cyclin D1/CDK4), c-Myc, $\mathrm{H}$-Ras and telomerase. Our approach provides for the 
efficient induction of tumorigenesis in primary pMEC by lentivirus-mediated expression of Tag, which upregulates multiple oncogenic pathways. This approach led to the formation of heterogeneous tumors, perhaps as a consequence of lentiviral transduction. Along these lines, transgenic expression of MT in the mouse mammary gland induced homogenous luminal, solid adenocarcinomas [53] whereas low levels of lentivirus-directed MT transformed both luminal and basal MEC, leading to concomitant heterogeneity among the tumors [54]. One further explanation may be variable Tag expression within pMEC subpopulations. Consistent with this postulate, the degree of Ras expression in transformed primary human MEC correlated with tumorigenicity in vivo [37]. Interestingly human MEC transformed with Ras-SV40 ST/LThTERT formed poorly differentiated squamous tumors when xenografted to the mammary fat pad of immunocompromised mice [37], similar to our findings with xenografted pMEC transformed by Tag. Although squamous differentiation is rare among human breast carcinomas, it is a phenotype that has been linked to Wnt activation [55], which has been associated with basal-like and receptor negative breast cancers [56]. Transformation of pMEC by alternative oncogenes may yield tumors with distinct histopathologies and hormone receptor profiles. In addition, our data indicate that selecting pMEC for $\mathrm{CD} 49 \mathrm{f}$ + enhanced the subsequent formation of luminal breast carcinomas, yielding tumors with luminal differentiated epithelium, whereas unenriched pMEC developed as normal ductal structures or fibrous tumors with and without squamous epithelium. It is possible that selection for CD49+/EpCAM+ cells in combination with culture conditions to increase ErbB3 expression over EGFR expression may increase the likelihood of generating luminal adenocarcinomas [35].

\section{Conclusions}

We have developed an approach for transforming porcine mammary epithelium. Our data point to similarities between the responses of pMEC and human MEC when xenografted to the mouse mammary fat pad, highlighting candidate differences in stromal requirements for oncogenesis across species. These studies lay the basis for investigating complex interactions underlying human breast cancer initiation and progression.

\section{Additional files}

Additional file 1: Figure S1. Plasmid maps of lentiviral vectors. (A) Map of the construct pLVX-IRES-tdTomato (CMV-tdTomato) wherein the CMV promoter directs tdTomato expression. The CMV promoter was replaced by the EF1a or PGK promoter to create EF1a-tdTomato or PGK-tdTomato. (B) To generate the pLVX-PGK-Tag-CMV-tdTomato vector, the pLVX-PGKTag vector was first created by replacing the IRES and tdTomato from the vector PGK-tdTomato with murine polyomavirus T antigen that encodes small T (ST), middle T (MT) and large T (LT) antigens. The CMV promoter and tdTomato coding sequence were sequentially added to the vector, creating a pLVX-PGK-Tag-CMV interim vector and the final expression vector pLVX-PGK-Tag-CMV-tdTomato. (PDF $155 \mathrm{~kb}$ )

Additional file 2: Figure S2. Transduction of PMEC by CMV-, EF1a- and PGK-TdTomato lentivirus. (A) Representative bright field and corresponding fluorescent images of primary PMEC at passage $0,7 \mathrm{~d}$ after transduction by CMV-tdTomato, EF1a-tdTomato or PGK-tdTomato lentiviral constructs. (B) Quantification of cells expressing tdTomato, as a measure CMV, EF1a and PGK promoter activity in PMEC. (PDF $1353 \mathrm{~kb}$ )

Additional file 3: Figure S3. Lentiviral integration following intraductal injection of lentivirus encoding CMV-tdTomato, EF1a-tdTomato or PGKtdTomato ( $n=9$ pigs/lentiviral construct). Mammary tissues were harvested $5 \mathrm{~d}$ post-injection, processed into paraffin and sections analyzed by immunohistochemical detection of dsRED (monomer of tdTomato) with using NovaRed for detection and a hematoxylin counterstain. The control section was not exposed to the dsRED antibody. The negative section is from a gland that was not injected with tdTomato expressing lentivirus. Scale bar $=100 \mu \mathrm{m}$. (PDF $624 \mathrm{~kb}$ )

Additional file 4: Figure S4. The promoter of large, middle and small T antigen (Tag) expression affected the rate of anchorage-independent colony formation. Representative images from three replicate experiments to measure soft-agar colony formation by PMEC ( $n=2$ wells/construct) transduced with CMV-Tag, EF1a-Tag, PGK-Tag or CMV-tdTomato lentivirus (MOI of 100). $\mathrm{NIH}-3 \mathrm{~T} 3$ cells were transduced with the same constructs as a positive control. Cells transduced by CMV-tdTomato served as negative control. (PDF $508 \mathrm{~kb}$ )

Additional file 5: Figure S5. Immunohistological features of the dense epithelial structures that appeared after isotopic engraftment of PGK-Tag transformed PMEC. Representative images detailing the expression of (A) estrogen receptor (B) progesterone receptor (C) vimentin and (D) cytokeratin. Scale bar $=100 \mu \mathrm{m}$. (PDF $9416 \mathrm{~kb}$ )

Additional file 6: Figure S6. Vimentin and cytokeratin expression in CD49f-/+ populations. Representative images depicting cytokeratin (red) and vimentin (green) expression in FACS sorted pMEC. Cells affixed to glass slides were stained by immunofluorescence for both pancytokeratin and vimentin. (A) CD140-CD49- pMEC. (B) CD140a-CD49f + pMEC at passages 2 (P2), 3 (P3) and 5 (P5). Vimentin-only positive cells are circled. (PDF $846 \mathrm{~kb}$ )

Additional file 7: Figure S7. Porcine mammary epithelial cells (pMEC) were transduced with PGK-Tag-CMV-TdTomato (PGK-Tag-CMV-tdT) lentivirus, cultured for $7 \mathrm{~d}$ then sorted using a MoFlo for (A) tdTomato fluorescence. (B) The sorted tdTomato + cells were plated into a soft agar assay alongside CMV-TdTomato transduced pMEC. (PDF $1741 \mathrm{~kb}$ )

Additional file 8: Figure S8. Representative images depicting differential in vitro morphology of populations of PMEC transduced by PGK-Tag-CMV-tdTomato lentivirus. Red fluorescence (RFP) is included to illustrate the percentage of transduced cells. (A) Transduced CD140aCD49f + pMEC retained a cobblestone morphology characteristic of MEC. (B) Transduced CD140a-tdTomato + pMEC from pig 27-3 grew as elongated cells. (C) Transduced CD140- pMEC from pig 28-3 developed foci in vitro rather than as a monolayer. (D) Transduced CD140tdTomato + pMEC from pig 28-6 grew as sheets of cobblestone epithelium with few foci. (PDF $1137 \mathrm{~kb}$ )

Additional file 9: Figure S9. Bright field and red fluorescence (RFP) in a xenograft subcutaneous tumor excised from a mouse carrying CD140-CD49+ PGK-Tag-CMV-tdTomato pMEC (ss020513_1) in hydrogel (A) or Matrigel (B). Scale bar $=1 \mathrm{~mm}$. (C) Bright field and RFP of a CD140- PGK-Tag-CMV-tdTomato tumor (ss082112) in Matrigel. Scale bar $=1 \mathrm{~mm}$. Bright field and RFP of microscopic growths in mammary fat pads injected with CD140- pMEC transduced with PGK-Tag-CMVtdTomato co-injected with (D) Matrigel (ss082112) or (E) hydrogel. Scale bar $=500 \mu \mathrm{m}$. (PDF $1166 \mathrm{~kb})$

\section{Abbreviations}

CMV: cytomegalovirus; EF1a: human elongation factor 1a; FBS: fetal bovine serum; H\&E: hematoxylin and eosin; LT: large $t$ antigen; MT: middle $t$ antigen;

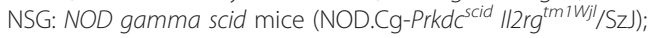


PGK: phosphoglycerate kinase; pMEC: porcine mammary epithelial cells; ST: small t antigen; Tag: T antigen; TDLU: terminal ductal lobular unit.

\section{Competing interests}

The authors declare that they have no competing interests.

\section{Authors' contributions}

AR-H and JT prepared the manuscript and RH critically reviewed the manuscript. AR-H, JT, RM and RH designed the experiments, AR-H, RM and JT conducted the experiments and $A B$ and $R C$ provided technical expertise and reviewed tumor histopathology. All authors read and approved the final manuscript.

\section{Acknowledgements}

We thank K. Parker, C. Sehnert and D. Sehnert for assistance with animals and facilities, E. Martínez-Alvarez, N. Breuner, A. Hanson, S. Santos, T. Lazzari and K. Scheier for technical assistance. O. Aina, N.E Hubbard, J.E. Walls at the UC Davis Center for Comparative Medicine performed the H\&E stains, immunohistochemistry and provided imaging assistance. This work was supported by a grant from the Department of Defense (BC098018, to R.C. Hovey and R.D. Cardiff), and the University of California, Davis Henry A. Jastro Research Scholarship Award (A.R. Rowson-Hodel). We gratefully acknowledge the infrastructure support of the Department of Animal Science, College of Agricultural and Environmental Sciences, and the California Agricultural Experiment Station of the University of California-Davis.

\section{Author details}

${ }^{1}$ Department of Animal Science, University of California Davis, One Shields Avenue, Davis, CA 95616, USA. ${ }^{2}$ Present Address: Department of Biochemistry and Molecular Medicine, University of California Davis School of Medicine, Sacramento, CA, USA. ${ }^{3}$ Present Address: USDA/ARS Children's Nutrition Research Center, Baylor College of Medicine, Houston, TX, USA. ${ }^{4}$ Center for Comparative Medicine, University of California Davis, One Shields Avenue, Davis, CA, USA.

\section{Received: 18 December 2014 Accepted: 17 July 2015}

\section{(2)}

\section{References}

1. Liu M and Hicklin D. Human tumor xenograft efficacy models. Tumor Models in Cancer Research. Cancer Drug Discovery and Development. Springer; 2011. p. 99-124.

2. Lin S, Lin Y, Nery JR, Urich MA, Breschi A, Davis CA, et al. Comparison of the transcriptional landscapes between human and mouse tissues. Proc Natl Acad Sci U S A. 2014;111(48):17224-9. doi:10.1073/pnas.1413624111.

3. Yue F, Cheng Y, Breschi A, Vierstra J, Wu W, Ryba T, et al. A comparative encyclopedia of DNA elements in the mouse genome. Nature. 2014:515(7527):355-64. doi:10.1038/nature13992.

4. Hovey R, McFadden T, Akers R. Regulation of mammary gland growth and morphogenesis by the mammary fat pad: a species comparison. J Mammary Gland Biol Neoplasia. 1999;4:53-68.

5. Wernersson R, Schierup MH, Jørgensen FG, Gorodkin J, Panitz F, Staerfeldt $\mathrm{HH}$, et al. Pigs in sequence space: a $0.66 \mathrm{X}$ coverage pig genome survey based on shotgun sequencing. BMC Genomics. 2005;6:70. doi:10.1186/1471-2164-6-70.

6. Lunney JK. Advances in swine biomedical model genomics. Int J Biol Sci. 2007;3(3):179-84.

7. Swindle MM, Makin A, Herron AJ, Clubb Jr FJ, Frazier KS. Swine as models in biomedical research and toxicology testing. Vet Pathol. 2012;49(2):344-56. doi:10.1177/0300985811402846.

8. Turner $\mathrm{C}$. The anatomy of the mammary gland of swine. In: Turner $\mathrm{C}$, editor. The mammary gland. The anatomy of the udder of cattle and domestic animals. Columbia: Lucas Brothers; 1952. p. 279-314.

9. Horigan KC, Trott JF, Barndollar AS, Scudder JM, Blauwiekel RM, Hovey RC. Hormone interactions confer specific proliferative and histomorphogenic responses in the porcine mammary gland. Domest Anim Endocrinol. 2009;37(2):124-38. doi:10.1016/j.domaniend.2009.04.002

10. Kensinger RS, Collier RJ, Bazer FW, Ducsay CA, Becker HN. Nucleic acid, metabolic and histological changes in gilt mammary tissue during pregnancy and lactogenesis. J Anim Sci. 1982;54(6):1297-308.
11. Russo J, Russo $\mid \mathrm{H}$. Development of the human breast. Maturitas. 2004;49(1):2-15. doi:10.1016/j.maturitas.2004.04.011.

12. Oftedal O, Dhouailly D. Evo-devo of the mammary gland. J Mammary Gland Biol Neoplasia. 2013;18(2):105-20. doi:10.1007/s10911-013-9290-8.

13. Hovey R, Trott J, Vonderhaar B. Establishing a framework for the functional mammary gland: from endocrinology to morphology. J Mammary Gland Biol Neoplasia. 2002;7(1):17-38. doi:10.1023/A:1015766322258.

14. Ghajar CM, Bissell MJ. Extracellular matrix control of mammary gland morphogenesis and tumorigenesis: insights from imaging. Histochem Cell Biol. 2008;130(6):1105-18.

15. Haslam SZ, Counterman L. Mammary stroma modulates hormonal responsiveness of mammary epithelium in vivo in the mouse. Endocrinology. 1991;129(4):2017-23.

16. Naylor MJ, Ormandy CJ. Mouse strain-specific patterns of mammary epithelial ductal side branching are elicited by stromal factors. Dev Dynam. 2002;225(1):100-5.

17. Russo J, Gusterson B, Rogers A, Russo I, Wellings S, van Zwieten M. Comparative study of human and rat mammary tumorigenesis. Lab Invest. 1990;62:244-78

18. Hovey RC, McFadden TB, Akers RM. Regulation of mammary gland growth and morphogenesis by the mammary fat pad: a species comparison. J Mammary Gland Biol Neoplasia. 1999;4(1):53-68. doi:10.1023/ a:1018704603426.

19. VanKlompenberg MK, McMicking HF, Hovey RC. Technical note: a vacuumassisted approach for biopsying the mammary glands of various species. J Dairy Sci. 2012;95(1):243-6. doi:10.3168/jds.2011-4565.

20. Hovey RC, Auldist DE, Mackenzie DD, McFadden TB. Preparation of an epithelium-free mammary fat pad and subsequent mammogenesis in ewes. J Anim Sci. 2000;78(8):2177-85.

21. Stampfer MR, Yaswen P and Taylor-Papadimitriou J. Culture of Human Mammary Epithelial Cells. In: Freshney I and Freshney M, editors. Culture of Epithelial Cells. John Wiley \& Sons: New York, USA; 2004

22. Barde I, Salmon P, Trono D. Production and titration of lentiviral vectors. Curr Prot Neurosci. 2010;4:1-23.

23. Byrne KM, Cheng X, Vierck J, Erickson S, Greene EA, Duckett S, et al. Use of a 96-well plate reader to evaluate proliferation of equine satellite cell clones in vitro. Methods Cell Sci. 1998;19(4):311-6.

24. Landua JD, Visbal AP, Lewis MT. Methods for preparing fluorescent and neutral red-stained whole mounts of mouse mammary glands. J Mammary Gland Biol Neoplasia. 2009;14(4):411-5.

25. Trott JF, Schennink A, Hovey RC. Cloning and expression of a unique short form of the porcine prolactin receptor. J Mol Endocrinol. 2011;46(1):51-62. doi:10.1677/jme-10-0101.

26. Shi S-R, Cote RJ, Wu L, Liu C, Datar R, Shi Y, et al. DNA extraction from archival formalin-fixed, paraffin-embedded tissue sections based on the antigen retrieval principle: heating under the influence of $\mathrm{pH}$. J Histochem Cytochem. 2002;50(8):1005-11. doi:10.1177/002215540205000802.

27. Trott JF, Freking BA, Hovey RC. Variation in the coding and 3' untranslated regions of the porcine prolactin receptor short form modifies protein expression and function. Anim Gen. 2014;45(1):74-86.

28. Vanklompenberg MK, Manjarin R, Trott JF, McMicking HF, Hovey RC. Late gestational hyperprolactinemia accelerates mammary epithelial cell differentiation that leads to increased milk yield. J Anim Sci. 2013;91(3):1102-11. doi:10.2527/jas.2012-5903.

29. Trott JF, Horigan KC, Gloviczki JM, Costa KM, Freking BA, Farmer C, et al. Tissue-specific regulation of porcine prolactin receptor expression by estrogen, progesterone, and prolactin. J Endocrinol. 2009;202(1):153-66. doi:10.1677/joe-08-0486.

30. Sheffield LG, Welsch CW. Transplantation of bovine mammary tissue to athymic nude mice: growth subcutaneously and in mammary gland-free fat pads. J Dairy Sci. 1986;69(4):1141-7. doi:10.3168/jds.S0022-0302(86)80513-6.

31. Sheffield LG, Welsch CW. Transplantation of human breast epithelia to mammary-gland-free fat-pads of athymic nude mice: Influence of mammotrophic hormones on growth of breast epithelia. Intl J Cancer. 1988;41(5):713-9.

32. Stingl J. Detection and analysis of mammary gland stem cells. J Pathol. 2009;217:229-41.

33. Cardiff RD. Validity of mouse mammary tumour models for human breast cancer: comparative pathology. Microsc Res Tech. 2001;52(2):224-30.

34. Kuperwasser C, Chavarria T, Wu M, Magrane G, Gray JW, Carey L, et al. Reconstruction of functionally normal and malignant human breast 
tissues in mice. Proc Natl Acad Sci U S A. 2004;101(14):4966-71. doi:10.1073/pnas.0401064101.

35. Verbeke S, Richard E, Monceau E, Schmidt X, Rousseau B, Velasco V, et al. Humanization of the mouse mammary gland by replacement of the luminal layer with genetically engineered preneoplastic human cells. Breast Cancer Res. 2014;16(6):504. doi:10.1186/s13058-014-0504-9.

36. Rowson AR, Daniels KM, Ellis SE, Hovey RC. Growth and development of the mammary glands of livestock: A veritable barnyard of opportunities. Semin Cell Dev Biol. 2012;23(5):557-66. doi:10.1016/j.semcdb.2012.03.018.

37. Elenbaas B, Spirio L, Koerner F, Fleming MD, Zimonjic DB, Donaher $J$, et al. Human breast cancer cells generated by oncogenic transformation of primary mammary epithelial cells. Genes Dev. 2001;15(1):50-65. doi:10.1101/gad.828901.

38. Rauner G, Leviav A, Mavor E, Barash I. Development of foreign mammary epithelial morphology in the stroma of immunodeficient mice. PLoS One. 2013;8(6), e68637. doi:10.1371/journal.pone.0068637.

39. Bao L, Matsumura $Y$, Baban D, Sun Y, Tarin D. Effects of inoculation site and Matrigel on growth and metastasis of human breast cancer cells. Brit J Cancer. 1994;70(2):228.

40. Hovey RC, Aimo L. Diverse and active roles for adipocytes during mammary gland growth and function. J Mammary Gland Biol Neoplasia. 2010;15(3):279-90. doi:10.1007/s10911-010-9187-8.

41. Casey HW, Giles RC, Kwapien RP. Mammary neoplasia in animals: pathologic aspects and the effects of contraceptive steroids. In: Lingeman C, editor. Carcinogenic hormones. Recent results in cancer research/Fortschritte der Krebsforschung/Progrès dans les recherches sur le cancer. Berlin Heidelberg: Springer; 1979. p. 129-60.

42. Mintz $B_{1}$ IIImensee $K$. Normal genetically mosaic mice produced from malignant teratocarcinoma cells. Proc Natl Acad Sci. 1975;72(9):3585-9.

43. Ronnov-Jessen L, Petersen O, Bissell M. Cellular changes involved in conversion of normal to malignant breast: The importance of the stromal reaction. Physiol Rev. 1996;76:69-125.

44. Adam S, Rund L, Kuzmuk K, Zachary J, Schook L, Counter C. Genetic induction of tumorigenesis in swine. Oncogene. 2006;26(7):1038-45.

45. Moule MG, Collins CH, McCormick F, Fried M. Role for PP2A in ARF signaling to p53. Proc Natl Acad Sci U S A. 2004;101(39):14063-6.

46. Schüchner S, Wintersberger E. Binding of polyomavirus small T antigen to protein phosphatase 2A is required for elimination of p27 and support of S-phase induction in concert with large T antigen. J Virol. 1999;73(11):9266-73.

47. Ozbun MA, Butel JS. Tumor suppressor p53 mutations and breast cancer: a critical analysis. Adv Cancer Res. 1995;66:71-141.

48. Varley J, Armour J, Swallow JE, Jeffreys AJ, Ponder BA, T'Ang A, et al. The retinoblastoma gene is frequently altered leading to loss of expression in primary breast tumours. Oncogene. 1989;4(6):725-9.

49. Lin EY, Jones JG, Li P, Zhu L, Whitney KD, Muller WJ, et al. Progression to malignancy in the polyoma middle T oncoprotein mouse breast cancer model provides a reliable model for human diseases. Am J Pathol. 2003:163(5):2113-26. doi:10.1016/s0002-9440(10)63568-7.

50. Dabrosin C, Palmer K, Muller WJ, Gauldie J. Estradiol promotes growth and angiogenesis in polyoma middle T transgenic mouse mammary tumor explants. Breast Cancer Res Treat. 2003;78(1):1-6.

51. Kendall SD, Linardic CM, Adam SJ, Counter CM. A network of genetic events sufficient to convert normal human cells to a tumorigenic state. Cancer Res. 2005;65(21):9824-8. doi:10.1158/0008-5472.can-05-1543.

52. Land H, Parada LF, Weinberg RA. Tumorigenic conversion of primary embryo fibroblasts requires at least two cooperating oncogenes. Nature. 1982;304(5927):596-602.

53. Guy CT, Cardiff RD, Muller WJ. Induction of mammary tumors by expression of polyomavirus middle T oncogene: a transgenic mouse model for metastatic disease. Mol Cell Biol. 1992;12(3):954-61.

54. Smith BA, Shelton DN, Kieffer C, Milash B, Usary J, Perou CM, et al. Targeting the PyMT oncogene to diverse mammary cell populations enhances tumor heterogeneity and generates rare breast cancer subtypes. Genes Cancer. 2012;3(9-10):550-63. doi:10.1177/1947601913475359.

55. Rosner A, Miyoshi K, Landesman-Bollag E, Xu X, Seldin DC, Moser AR, et al. Pathway pathology: histological differences between ErbB/Ras and Wnt pathway transgenic mammary tumors. Am J Pathol. 2002;161(3):1087-97.

56. Polakis P. Wnt signaling in cancer. Cold Spring Harb Perspect Biol. 2012;4(5):1-13. doi:10.1101/cshperspect.a008052.

\section{Submit your next manuscript to BioMed Central and take full advantage of:}

- Convenient online submission

- Thorough peer review

- No space constraints or color figure charges

- Immediate publication on acceptance

- Inclusion in PubMed, CAS, Scopus and Google Scholar

- Research which is freely available for redistribution

Submit your manuscript at www.biomedcentral.com/submit 